\title{
Endodontic root canal treatment performed by undergraduate dental students: Identification of technical standard and post-endodontic restorations
}

\author{
Norazlina Mohammad a, ", Faizah Abd Fatah a, Norzalina Ghazali b, Ahmad Zaim Muhamad c, \\ Nurhidayah Hamir ${ }^{c}$
}

a Department of Conservative Dentistry and Prosthodontic, Faculty of Dentistry, Universiti Sains Islam Malaysia, Bandar Baru Nilai, 71800, Nilai, Negeri Sembilan, Malaysia

b Department of Paediatric Dentistry and Orthodontics, Faculty of Dentistry, Universiti Sains Islam Malaysia, Bandar Baru Nilai, 71800, Nilai, Negeri Sembilan, Malaysia

c Dental Division, Ministry of Health, Ministry of Health, Federal Government Administrative Centre, 62590 Putrajaya, Malaysia

*Corresponding author: norazlina79@usim.edu.my

\section{Article history}

Received 1 April 2018

Revised 25 April 2018

Accepted 8 May 2018

Published Online 25 August 2019

\begin{abstract}
Root canal treatment (RCT) is a procedure to eliminate pulpal diseases with the aim to promote healing of the periradicular tissue. The RCT conducted must be of high technical standard and achieve a good quality endodontic work (GQEW) to ensure successful outcome and prolonged retention of the teeth in oral cavity. Previous studies reported poor outcome of RCT conducted by the undergraduate dental students. There is limited report documented on the quality of RCT performed by the dental students in Malaysia. The aim of this study was to identify the technical standards of the RCT and types of post-endodontic restoration placed by USIM undergraduate dental students. The radiographic obturation quality from 274 root filled teeth were evaluated against several indices. The data was analyzed using SPSS version 21. Post treatment radiographs indicated that $84.62 \%$ of the RCT have adequate density indicating good apical seal. Meanwhile, for obturation level, the root canal filling that ends $0-2 \mathrm{~mm}$ (optimal), $>2 \mathrm{~mm}$ away (inadequate), and beyond apex (extrusion) were $84.59 \%, 5 \%$, and $10.77 \%$, respectively. Teeth with GQEW, having both adequate root filling length and complete obturation were found in 194 (74.6\%) teeth. McNemar's test revealed significant reduction in post-treatment periapical index $(p<0.001)$ indicating good periapical healing. Permanent restoration was only placed in $48 \%$ of the teeth. In conclusion, the RCT conducted by USIM undergraduate dental students have a good technical standard. Placements of post-endodontic permanent restoration need to be emphasized in the curriculam to ensure long-term success of the endodontically treated teeth.
\end{abstract}

Keywords: Root canal treatment, undergraduate students, Malaysia, technical standard, obturation quality, post-endodontic restoration

(C) 2019 Penerbit UTM Press. All rights reserved

\section{INTRODUCTION}

Teeth are involved in several functions including mastication, proprioception, aesthetic, and speech. However a tooth may become necrose and lose its vitality due to carious disease that progresses into the pulp or when the pulp is mechanically or traumatically exposed, requiring root canal treatment (RCT). Root canal treatment is a procedure that uses biologically-acceptable mechanical treatment in the root canal system to eliminate pulpal and periradicular diseases and to promote healing and repairing of the periradicular tissue (Hui et al., 2004).

According to Imura et al., 2007, the definition of adequate RCT is when the treatment is done with thorough and meticulous technique. This will then result in successful treatment outcome and prolong tooth retention in the patient's dentition. The indicators of successful RCT outcomes are absence of clinical sign and symptom, normal periodontium, and negative bacterial culture (Estrela et al., 2014). On the contrary, root canal treatment that is not conducted adequately or has had iatrogenic error such as underfilling, overfilling, missed canal, coronal leakage, and procedural error (perforations, separated instruments and ledge) during the treatment may cause persistent of signs and symptoms due to previous infection or reinfection and in the end result in failure of root canal treatment (Lin et al., 2005, Ashley et al., 2001). Therefore, it is essential to ensure that the RCT is conducted following the recommended technical standard. European Society of Endodontology has proposed a quality guideline for root canal treatment in 1994. In this document, the apical obturation length need to be in within $0-2 \mathrm{~mm}$ from apex with good density to be classified as having a good quality endodontic work (GQEW).

Apart from a good apical seal obtained from obturation, apical periodontal healing also depends significantly on the final coronal restoration (Ray \& Trope, 1995). This is because salivary microleakage is one of the major causes of endodontic failure due to bacterial reinfection of the root canal system and periapical area. Thus, placement of an immediate and effective coronal seal following root canal treatment is deemed mandatory.

Generally, RCT that were conducted by qualified dentists had good treatment outcome regardless of anterior or posterior dentition. However a lower treatment outcome was found among dental undergraduate students. This maybe due to lack of skills, inadequate experience and time constrain (Labbaf et al., 2014) during the 
undergraduate studies. It could also be related to the endodontic teaching, which may have some impact on the quality of the root canal treatment provided. According to the European Undergraduate Curriculum Guidelines for Endodontology, the dental graduates must be rendered competent to perform root canal treatment procedures on patient upon graduation (De Moor et al., 2013).

In Malaysia, root canal treatment is considered part of the clinical training in the dental curriculum. In USIM, it is taught during undergraduate study under the supervision of endodontist and experienced conservative dentistry specialists. The students need to undergo pre-clinical training and pass the endodontic competency test on extracted tooth, before they are allowed to start performing root canal treatment on patients. Treatment manual and specific examination and diagnosis form are provided to guide the students to perform root canal treatment procedure. This is to ensure that the root canal treatment is conducted following the recommended technical standard. However, the outcome of the root canal treatment performed by the USIM dental undergraduate students has not been previously assessed. Therefore, it is necessary to evaluate the quality of root canal treatment performed in order to improve the pre-clinical and clinical training of undergraduate endodontic curriculum in USIM.

\section{MATERIAL AND METHODOLOGY}

\section{Selection of cases}

This is a cross-sectional of secondary data study involving teeth treated by USIM undergraduate dental students from the year of 2010 to 2017. After following the inclusion and exclusion criteria, a total of 274 root treated teeth were recruited into this study. The data on the root treated teeth were obtained from the students' logbook, patients' folder, and digital radiographs. The inclusion and exclusion criteria are as presented in Table 1, which were adopted from previous study done by Yousuf et al., 2015.

Table 1 The inclusion and exclusion criteria for radiographic assessment.

\begin{tabular}{|c|c|}
\hline Inclusion criteria & Exclusion criteria \\
\hline $\begin{array}{l}\text { Patients aged between } 12 \text { to } \\
60 \text { years }\end{array}$ & Teeth with blocked canal \\
\hline $\begin{array}{l}\text { Permanent teeth with } \\
\text { complete root formation }\end{array}$ & $\begin{array}{l}\text { Permanent teeth with open } \\
\text { apices }\end{array}$ \\
\hline $\begin{array}{l}\text { Presence of good quality } \\
\text { radiographs that showed the }\end{array}$ & $\begin{array}{l}\text { External and lateral root } \\
\text { resorption }\end{array}$ \\
\hline $\begin{array}{l}\text { entire length of the root and } \\
\text { the periapical area }\end{array}$ & $\begin{array}{l}\text { Periapical pathology (such as } \\
\text { cysts and tumors) }\end{array}$ \\
\hline & $\begin{array}{l}\text { Advanced periodontal conditions } \\
\text { or perio-endo lesions }\end{array}$ \\
\hline & $\begin{array}{l}\text { Cases with unreadable } \\
\text { radiographs }\end{array}$ \\
\hline & Re-treatment cases \\
\hline
\end{tabular}

Ethical approval was obtained from the Faculty of Dentistry USIM prior to the study.

\section{Evaluation of the quality of root canal treatment}

Two examiners were calibrated against an endodontist specialist, the goal standard for radiographic interpretation using the periapical index (PAI). The selected samples of radiographs preoperative PAI and postoperative PAI were rated until achieved a strong agreement of Cohen's kappa score. The inter-examiner and intra-examiner agreement were 0.7 .

Data collection form had been generated by adapting several indices and criteria from previous research. The form was divided into two parts, that showed assessment of the obturation quality and identification of the coronal seal. The criteria were assessed from digital radiographs and obtained from the patient's folders respectively.

The technical standard of root canal treatment was evaluated based on the obturation density and obturation level, following the guidelines of European Society of Endodontology (1994). The obturation density was evaluated according to the index adapted from Segura-Egea et al., 2004. Meanwhile the obturation level was assessed from the end of obturation to the radiographic apex, adapted from the index indicated by Smadi et al., 2015. The descriptions of the indices are shown in Table 2 below.

\section{Evaluation of the periapical bone status}

The periapical bone status was evaluated using Periapical Index (PAI) adopted from Ørstavik et al., 1986 ranging from PAI 1 (normal periapical bone structure) to PAI 5 (severe apical periodontitis with exacerbating feature) as shown in Figure 1. For each root-filled tooth, at least two periapical radiographs were examined. The pre-operative radiograph was assessed as the baseline PAI and obturation radiograph as the post-operative radiograph. In cases of multirooted teeth, only the root canal presented with the worst PAI score was evaluated.

Table 2 The criteria and index of obturation level and obturation density.

\begin{tabular}{lll}
\hline Parameters & Criteria & \multicolumn{1}{c}{ Codes and definition } \\
\hline $\begin{array}{l}\text { Obturation } \\
\text { density }\end{array}$ & Adequate & $\begin{array}{l}1=\text { Adequate in the coronal } 1 / 2 \text { of the root } \\
\text { filling }+ \text { adequate in the apical } 1 / 2 \text { of the } \\
\text { root filling (optimal) }\end{array}$
\end{tabular}

$2=$ Inadequate in the coronal $1 / 2$ of the root filling + adequate in the apical $1 / 2$ of the root filling (acceptable)

Inadequate $3=$ Adequate in the coronal $1 / 2$ of the root filling + inadequate in the apical $1 / 2$ of the root filling

$4=$ Inadequate in the coronal $1 / 2$ of the root filling + inadequate in the apical $1 / 2$ of the root filling

$\begin{array}{llllll}\begin{array}{l}\text { Obturation } \\ \text { level }\end{array} & \text { Adequate } & \begin{array}{l}1=\text { Root filling ending } \leq 2 \mathrm{~mm} \\ \text { radiographic apex (optimal) }\end{array} & \\ \end{array}$

2=Flush, root filling ending at the radiographic apex (flush)

Under $\quad 3=$ Pulpotomy, material seen only in the pulp chamber

4=Root filling ending $>2 \mathrm{~mm}$ from radiographic apex

Over $\quad 5=$ Over-filling, root filling material seen in the periapical area

A root canal filling having both criteria of adequate obturation density in the apical $1 / 2$ and obturation length ending $\leq 2 \mathrm{~mm}$ from radiographic apex, was classified as having a good-quality endodontic

Figure 1 The Periapical Index (PAI) (Ørstavik et al., 1986).

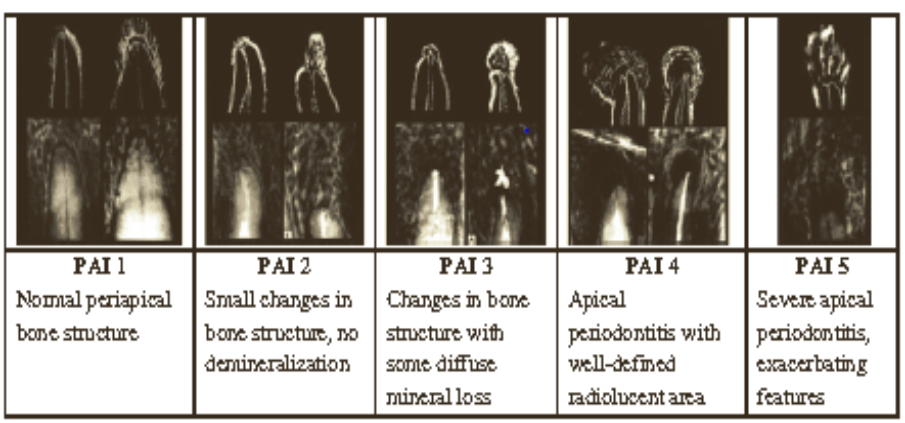

The periapical index (PAI) was further categorized as sound periapical bone or diseased periapical bone. According to Kirkevang 
et al., 2015, PAI score 1 and 2 were categorized as sound bone, while PAI score 3, 4, and 5 indicated the presence of diseased bone.

\section{Identification of the final coronal restoration}

The types of coronal restoration had been identified whether it was temporary, semi-permanent, or permanent restoration from the clinical case notes documented in patients' folder.

\section{Data analysia}

The data had been analyzed using descriptive analysis SPSS version 21.0. The change in the PAI score was further analyzed using McNemar analysis.

\section{RESULTS}

The undergraduate dental students conducted primary root canal treatments in 274 teeth during the study period. However, only 260 teeth met the inclusion criteria and recruited into the radiographic assessment.

Table 3 shows the quality of the root canal treatment pertaining to the obturation density and length. A total of $84.62 \%$ from the 260 root treated teeth showed adequate obturation density, which was $58.05 \%$ in both coronal and apical half, and $26.54 \%$ in the apical half. $84.59 \%$ showed adequate obturation level, in which the obturation ends in within 0 to $2 \mathrm{~mm}$ from radiographic apex. Meanwhile, $5 \%$ were underfilled and $10.77 \%$ were overfilled.

Table 3 The density and level of root fillings.

\begin{tabular}{lllc}
\hline Parameters & \multicolumn{3}{l}{ Criteria } \\
\hline Obturation & Adequate & Optimal & $151(58.08)$ \\
density & & Acceptable & $69(26.54)$ \\
\cline { 2 - 4 } & Inadequate & Apical & $28(10.77)$ \\
& & Coronal+Apical & $12(4.61)$ \\
\hline Obturation & Adequate & Optimal & $151(58.08)$ \\
level & & Flush & $69(26.54)$ \\
\cline { 2 - 4 } & Inadequate & Under & $13(5)$ \\
& & Over & $27(10.38)$ \\
\hline
\end{tabular}

GQEW that was defined as having both adequate root canal filling length and complete obturation was found in 194 (74.6\%) root canals. The PAI score at baseline and during obturation is showed in Table 4. 130 of the teeth were categorized as diseased at baseline (prior to root canal treatment) and 130 having sound and normal periapical structures. 39\% $(n=51)$ from the diseased teeth have a sound and normal periapical structure during obturation phase. Overall, $66.5 \%$ $(n=173)$ of the root treated teeth has a sound periapical status upon root canal treatment completion. 3\% $(\mathrm{n}=8)$ of the sound periapical status at baseline showed higher PAI score during obturation. $30.4 \%$ $(n=79)$ of the teeth were still presented with periapical lesion during obturation (PAI score 3,4 and 5). McNemar's test revealed significant change in PAI index post-operatively with $\mathrm{p}$ value $<0.001$.

Table 4 The Periapical Index (PAI) before and after root canal treatment.

\begin{tabular}{ccccc}
\hline & & \multicolumn{2}{c}{ Post-operative } & \multirow{2}{*}{ Total } \\
\cline { 3 - 4 } & & Sound & Diseased & \\
\hline Pre-operative & Sound & 122 & 8 & 130 \\
& Diseased & 51 & 79 & 130 \\
\hline \multicolumn{2}{c}{ Total } & 173 & 87 & 260
\end{tabular}

The types of final coronal restorations placed for the root treated teeth are shown in Table 5. 48\% from 274 root treated teeth were permanently restored with extracoronal and intracoronal restorations at $36 \%$ and $12 \%$, respectively. However the remaining of the roottreated teeth are still in semi-permanent restorations (core material) and temporary restorations.
Table 5 The types of coronal seal of the root treated teeth.

\begin{tabular}{cc}
\hline Types of restoration & Total \\
\hline Permanent extracoronal & $98(36 \%)$ \\
Permanent intracoronal & $33(12 \%)$ \\
Semi-permanent amalgam & $52(19 \%)$ \\
Semi-permanent composite & $44(16 \%)$ \\
Temporary Zink Oxide Eugenol & $11(4 \%)$ \\
Temporary Glass lonomer Cement & $33(12 \%)$ \\
Not recorded & $3(1 \%)$ \\
\hline
\end{tabular}

\section{DISCUSSION}

During the time span of 6 years, the undergraduate dental students have conducted primary root canal treatment on 274 teeth. The yearly enrolment of new undergraduate students in USIM is 35 students per year. Each student is required to perform 3 single canals in at least 2 anterior/premolar teeth and one molar tooth before graduation. The RCT data was obtained from the graduated students logbook. Only 105 logbooks were available during sample recruitment that belonged to three batches of dental graduates.

From 260 teeth that fulfilled the inclusion criteria for radiographic evaluation in this study, $81.03 \%$ of the RCT teeth have adequate obturation density and $78.4 \%$ have adequate endodontic obturation level. However when these measures were assessed simultaneously following the criteria indicated by European Society of Endodontology (1994), only $74.6 \%(n=94)$ teeth can be categorized as having GQEW and of high technical standards. These findings were higher compared to other similar studies. A study done in Dublin Dental University reported that there was lower quality of obturation level at 69\% (Kumar \& Duncan, 2012). Another study conducted in University of Jordan, only $61.5 \%$ of treated teeth were adequate in length and $50.5 \%$ were adequate in density (Smadi et al., 2015). In the present study, the obturation density scored better than the obturation length. Poor obturation density at corrected working length may indicate that the root canal has been adequately cleaned to the root end but poorly filled. Meanwhile, an underfilled root canal would give an idea that the apical portion of the root canal has not been instrumented and cleaned to the root end. Hence, the tooth may still harbor bacteria (Kirkevang et al. 2000), which will cause persistent infection and lead to failure of the endodontic treatment (Siqueira et al., 2001).

Quality of root filling obturation and post-treatment restorative status have a strong effect on the outcome of root canal treatment. The periapical health and improved outcome of RCT were associated with dense apical root fillings and obturation length of $0-2 \mathrm{~mm}$ from apex (Saunders et al., 1997). Several indices had been introduced in order to monitor the change in the periapical status of the endodontically treated teeth, which will indicate healing of periradicular tissues, progression of the disease or occurrence of new disease following root canal treatment. Ørstavik et al., 1986 utilized Brynolf's histologic and radiographic appearances findings to develop a 5-point ordinal index namely the Periapical Index (PAI). The full scale PAI has been shown to produce a distinct prognostic value for monitoring of the periapical disease. In this study, 39\% ( $\mathrm{n}=51)$ from the diseased teeth showed evident transition to sound periapical status upon obturation, which might contribute to the $66.5 \%$ of healing of the periapical bone after obturation. This finding may indicate that these teeth have a sound/good immediate outcome upon treatment completion with significant change in the PAI score $(\mathrm{p}<0.001)$. In USIM, it is documented in the treatment protocol that all of the teeth indicated for root canal treatment need to be initially restored with pre-endodontic restoration upon formulation of treatment plan. During this early treatment phase, the pulp is removed and root canal is disinfected with irrigation material and filled with intracanal medicament. This procedure will facilitate healing of the periapical tissues, much earlier before the actual endodontic treatment phase commenced. On the other hand, $3 \%(n=8)$ of the teeth that had a sound periapical status at baseline showed poor PAI score during obturation. This may indicate the presence of re-infection during the course of root canal treatment and thus need to be observed more frequently through prolong review recall. Meanwhile, $30.4 \%(n=79)$ of the teeth were still presented with 
periapical lesion with no active infection during obturation. These teeth with uncertain prognosis during obturation may require longterm review and reassessment for up to 4 years (European Society on Endodontology, 2006), to monitor the periapical healing and to determine its prognosis.

In this study, $48 \%$ of endodontic treated teeth had been restored with permanent restoration. Unfortunately, $51 \%$ are still in semipermanent and temporary restoration. This condition is alarming as fracture or loss of temporary restoration may result in contamination of the obturated root canal system. It is documented that $63.9 \%$ of the teeth with inadequate coronal restorations had a diseased apical periodontium (Kirkevang et al., 2000). Hence, the permanent coronal restoration should be placed as rapidly as possible, ideally in the first week after treatment (Siqueira, 2001). The delay in providing postendodontic permanent restoration in this study is probably due to some of the RCT cases being conducted by final year students at the end of their study. Therefore, they were unable to place permanent restoration before they completed their study. This delay in placement of permanent restoration could predispose the root treated teeth to coronal leakage (Siqueira et al., 1999) and subsequent risk of root canal treatment failure (Saunders et al., 1994). Hence there is a need to further assess the condition of coronal restoration and its impact on the healing of the periapical tissues through review recall. The findings from this study will serve as a valuable input for the generation of the faculty's endodontic pre-clinical practical manual and clinical practical guidelines in the future.

\section{CONCLUSION}

From this study, the USIM undergraduate dental students performed good quality endodontic work (GQEW) with good technical standard and extracoronal restorations are the most common postendodontic restoration placed.

\section{ACKNOWLEDGEMENT}

The authors gratefully acknowledge Universiti Sains Islam Malaysia (USIM) in providing the research fund (Research code: PPP/USG-0216/FPG/30/17416).

\section{REFERENCES}

Ashley, M., Harris I. (2001). The assessment of the endodontically treated tooth. Dent Update. 28(5):247-252.

Consensus report of the European Society of Endodontology on quality guidelines for endodontic treatment. (1994). Int Endod J. 27(3):115-124.

De Moor, R., Hülsmann, M., Kirkevang, L. L., Tanalp, J., Whitworth, J. (2013). Undergraduate curriculum guidelines for endodontology. Int Endod J. 46(12):1105-1114

Estrela, C., Holland, R., Estrela, C. R., Alencar, A. H., Sousa-Neto, M. D., Pécora, J. D. (2014). Characterization of successful root canal treatment. Braz Dent J. 25(1):3-11.

European Society of Endodontology. (2006). Quality guidelines for endodontic treatment: consensus report of the European society of endodontology. Int Endod J. 39:921-930.

Hossein, L., Gita, R., Shahriar, S., Hadi, A., Fatemeh, M. M. (2014). Retrospective evaluation of endodontic procedural errors by under and post-graduate dental students using two radiographic systems. J Islam Den. Assoc Iran. 26(4):245-54.

Hui, K. C., Chen, N. N., Koh, E. T., Lam, E. C., Lim, K. C., Sum, C. P. (2004) Guidelines for root canal treatment. Singapore Dent J. 26(1):60-62.

Imura, N., Pinheiro, E. T., Gomes, B. P., Zaia, A. A., Ferraz, C. C., SouzaFilho, F. J. (2007). The outcome of endodontic treatment: a retrospective study of 2000 cases performed by a specialist. J Endod. 33(11):12781282 .

Kirkevang, L. L., Ørstavik, D., Bahrami, G., Wenzel, A., Vaeth, M. (2017). Prediction of periapical status and tooth extraction. Int Endod J. 50(1):514.

Kirkevang, L. L., Ørstavik, D., Hörsted-Bindslev, P., Wenzel, A. (2000) Periapical status and quality of root fillings and coronal restorations in a Danish population. Int Endod J. 33(6):509-515.

Kumar, M., Duncan, H. F. (2012). Radiographic evaluation of the technical quality of undergraduate endodontic 'competence' cases in the Dublin Dental University Hospital: An audit. J Ir Dent Assoc. 58(3):162-166.

Lin, L. M., Rosenberg, P. A., Lin, J. (2005). Do procedural errors cause endodontic treatment failure? J Am Dent Assoc. 136(2):187-193.

Ørstavik, D., Kerekes, K., Eriksen, H. M. (1986). The periapical index: A scoring system for radiographic assessment of apical periodontitis. Endod Dent Traumatol. 2(1):20-34.

Ray, H. A., Trope, M. (1995). Periapical status of endodontically treated teeth in relation to the technical quality of the root filling and the coronal restoration. Int Endod J. 28(1):12-18.

Saunders, W. P., Saunders, E. M., Sadiq, J., Cruickshank, E. (1997). Technical standard of root canal treatment in an adult Scottish sub-population. $\mathrm{Br}$ Dent J. 182(10):382-386.

Saunders, W. P., Saunders, E. M. (1994). Coronal leakage as a cause of failure in root-canal therapy: A review. Endod Dent Traumatol. 10(3):105-8. Review.

Segura-Egea, J. J., Jiménez-Pinzón, A., Poyato-Ferrera, M., Velasco-Ortega, E. Ríos-Santos, J. V. (2004). Periapical status and quality of root fillings and coronal restorations in an adult Spanish population. Int Endod J. 37(8):525-530

Siqueira, J. F. Jr., Rôças, I. N., Abad, E. C., Castro, A. J., Gahyva, S. M., Favier,i A. (2001). Ability of three root-end filling materials to prevent bacterial leakage. J Endod. 27(11):673-675.

Siqueira, J. F. Jr., Rôças, I. N., Lopes, H. P., de Uzeda, M. (1999). Coronal leakage of two root canal sealers containing calcium hydroxide after exposure to human saliva. J Endod. 25(1):14-16.

Siqueira, J. F. Jr. (2001). Aetiology of root canal treatment failure: why welltreated teeth can fail. Int Endod J. 34(1):1-10.

Smadi, L., Hammad, M., El-Ma'aita, A. M. (2015). Evaluation of the quality of root canal treatments performed by dental undergraduates: is there a need to review preclinical endodontic courses? Am. J. Educ. Res. 3(12):1554-1558.

Yousuf, W., Khan, M., Mehdi, H. (2015). Endodontic procedural errors: Frequency, type of error, and the most frequently treated tooth. Int $J$ Dent.vol2015:673914. 